\title{
Plant response to touch affects the behaviour of aphids and ladybirds
}

\author{
Dimitrije Markovic $\cdot$ Robert Glinwood • \\ Ulf Olsson • Velemir Ninkovic
}

Received: 5 August 2013/Accepted: 19 March 2014/Published online: 4 April 2014

(C) The Author(s) 2014. This article is published with open access at Springerlink.com

\begin{abstract}
Touching between leaves of the same plant and/or by neighbouring plants is one of the most common mechanical stimuli to which an individual plant has to respond on a daily basis. The possible ecological implications of a plant's response to touch on plant-insect interactions have not been explicitly investigated. We examined whether plant response to 1 min daily touching over a period of 6 days affects host plant acceptance by the bird cherry-oat aphid Rhopalosiphum padi L. on maize and by the black bean aphid Aphis fabae Scop. on bean, as well as olfactory preference of an aphid predator, seven-spotted ladybird Coccinella septempunctata L. Maize plants responded to touch with significant reduction in plant height, total plant biomass, leaf weight, leaf surface, shoot/ root ratio and specific leaf area (SLA), while bean plants responded with reduced stem height and reduced SLA. Both aphid species showed significantly reduced acceptance of touched plants compared with untouched plants. The two aphid species and male and female ladybirds preferred volatiles from untouched plants over those from touched plants. Volatiles in the headspace of touched and
\end{abstract}

Handling Editor: John F. Tooker.

\section{Markovic}

Faculty of Agriculture, University of Banja Luka, Bulevar Vojvode Petra Bojovica 1a, 78000 Banja Luka, Bosnia and Herzegovina

R. Glinwood · V. Ninkovic ( $\square)$

Department of Ecology, Swedish University of Agricultural

Sciences, PO Box 7044, 75007 Uppsala, Sweden

e-mail: velemir.ninkovic@slu.se

U. Olsson

Department of Economy, Swedish University of Agricultural Sciences, Box 7090, 75007 Uppsala, Sweden untouched plants were collected and identified. Stepwise discriminant analyses identified $(E)$-nerolidol and $(E)-\beta$ caryophyllene in maize and 6-methyl-5-hepten-2-one and an unidentified sesquiterpene in bean as the best discriminating compounds in the volatile profiles of touched plants. Our study suggests that touch-induced changes in plants can potentially affect host plant selection by aphids and habitat searching by ladybirds. Thus, touch-induced changes in plants may have significant effects at higher trophic levels.

Keywords Rhopalosiphum padi $\cdot$ Aphis fabae . Coccinella septempunctata · Volatile cues · Aphid host plant acceptance $\cdot$ Habitat selection

\section{Introduction}

Lacking the ability to move away from stressful situations, plants have developed very sensitive mechanisms to perceive and respond to different environmental conditions. Touch is one of the most common mechanical stimuli to which plants have to respond in order to quickly adapt their growth and ensure survival in a complex and dynamic environment (Telewski 2006). Thigmo responses have been observed in different plant species (Jaffe 1973) with the main focus on agricultural crops (Braam 2005). Plants with specialised sensory cells respond immediately (Forterre et al. 2005), while other plants show visible morphological modifications induced by touching over longer periods of time, from days to weeks (Telewski 2006; Liu et al. 2007; Chehab et al. 2012).

The role of touching in plant-insect interactions is still poorly understood. Cahill et al. (2001) noticed that physical handling of plants during measurements can have negative 
or positive effects on the occurrence of herbivores. Many plants are able to perceive touch and respond with physiological, morphological or biochemical adjustments (Braam 2005). Such changes in plant status may be detected by insects providing them with reliable cues about host plant quality. It has been shown that most aphid species are closely adapted to host plants and their relationship can be considered as intimate since they are very sensitive to small changes in plant quality (Pettersson et al. 2007). The possible influence of touch-induced response in plants on aphid host plant selection and settling has so far been overlooked.

Seven-spotted ladybirds, Coccinella septempunctata (L.) can play a prominent role in aphid control. As a polyphagous predator, $C$. septempunctata may exploit several different cues released by plants to increase the efficiency of habitat searching, even in the absence of aphids (Pettersson et al. 2008; Honěk and Martinková 2008; Ninkovic et al. 2011). The efficiency of the searching behaviour of a predator depends on mechanisms for identifying habitats where the probability of finding herbivores is increased. To our knowledge, there are no reports showing whether touch-induced changes in plants could affect insect behaviour at the third trophic level, such as ladybirds.

The overall aim of this study, therefore, was to determine whether plant touch responses affect the foraging behaviour of herbivores and their natural enemies. Four specific questions were investigated:

1. Does plant touch response influence aphid host plant acceptance?

2. Does plant touching change aphid olfactory preferences?

3. How do ladybirds respond to odours released from touched plants?

4. Do touch responses of different plant species have the same implications for other trophic levels (aphids and ladybirds)?

\section{Materials and methods}

\section{Insects}

The bird cherry-oat aphid, Rhopalosiphum padi L., one of the key pests of maize, and the black bean aphid, Aphis fabae Scop., one of the most common pests on bean plants, were selected as model insect herbivores. Rhopalosiphum padi was reared on barley, Hordeum vulgare L. (cv Golf) in multi-clonal cultures in a greenhouse under the same conditions as for plants. Aphis fabae was reared on broad bean, Vicia faba L. (cv Button dwarf). Both aphid species used in the experiments were wingless, mixed-instar individuals. They were collected from the cultures immediately prior to bioassay.

Adults of seven-spotted ladybirds C. septempunctata were collected from their natural habitat near Uppsala, Sweden $\left(59^{\circ} 47^{\prime} \mathrm{N}, 17^{\circ} 39^{\prime} \mathrm{E}\right)$ and reared through several generations before being used in experiments. They were kept in cages $(40 \times 40 \times 80 \mathrm{~cm})$ with potted barley plants (cv Golf) infested with aphids, $R$. padi and Sitobion avenae (F.). Rapeseed, Brassica napus L. and white mustard, Sinapsis alba L. plants were used as a source of pollen. Insects and plants were kept in a room with a controlled environment: L16:D8 light cycle with one lamp (Hortilux Schréder, HPS 400 Watt, Holland) per square metre, $18-22{ }^{\circ} \mathrm{C}$ temperature and $80 \%$ relative humidity.

Plants

Seeds of dwarf bean Phaseolus vulgaris L. (cv Saxa) (Bröderna Nelson, Tingsryd, Sweden) and maize seeds Zea mays L. (cv Delprim) (Delley Seeds and Plants Ltd Delley, Switzerland) were used in the experiments. Before sowing, the bean seeds were germinated in Petri dishes on filter paper for $24 \mathrm{~h}$. Prior to sowing, maize seeds were sterilised in $70 \%$ ethanol for $3 \mathrm{~min}$ and rinsed twice in deionized water, then the seeds were placed in a solution of chlorine and water in a ratio 1:1 for $15 \mathrm{~min}$ and rinsed again four times in deionized water.

Bean and maize plants were grown in plastic pots $(9 \times 9 \times 7 \mathrm{~cm})$ in garden potting soil (Hasselfors, Sweden) with one seed per pot in a greenhouse at $18-22{ }^{\circ} \mathrm{C}$, with a L16:D8 light cycle. Natural light was supplemented by light from HQIE lamps (Hortilux Schréder, HPS 400 Watt, Holland)—one lamp per square metre. Each plant was watered via an automated water drop system daily at 8 a.m. ( $2 \mathrm{~h}$ into the photoperiod). Six days after sowing, maize plants at the two leaf stage and bean plants with two open leaves were selected for uniformity in size and moved into clear Perspex cages.

Touching treatment

Plants were placed inside modified Perspex cages (each $10 \times 10 \times 40 \mathrm{~cm})$, with an opening $(7 \mathrm{~cm}$ diameter $)$ in the front side (Ninkovic et al. 2002). Pots with test plants were placed in Petri dish lids to prevent any contact with root exudates from neighbouring plants. Air entered the cage through an opening in the cage wall and was extracted through a Teflon tube attached to a vacuum tank. The extracted air was then vented outside the room by an electric fan to prevent volatile interaction between plants. Thus, plants in this system were not expected to interact with each other in any way. Airflow through the cages was $1.31 \mathrm{~min}^{-1}$. Each of the treatments was repeated 18 times. 
Each block consisted of touched and untouched plants of maize and bean, respectively.

Plant touch treatments started after the plants had spent $24 \mathrm{~h}$ in the Perspex cages. A soft squirrel hair face brush (Rouge) (Lindex, Sweden) was used. The second leaves of maize were carefully brushed from the leaf base to the top, while both bean leaves were brushed back and forth, using the modified method previously described (Montgomery et al. 2004; Liu et al. 2007; Anten et al. 2010). This treatment was chosen to simulate the plant response to mechanical contact with a neighbouring plant. Until the last day of the experiment, leaves of maize and bean plants did not have any contact with cage walls. Treated maize and bean plants were brushed in the morning for $1 \mathrm{~min} /$ day for a period of 6 days. This period was based on the time needed by maize plants to reach the top of the cage. All maize and bean plants treated by touching did not have any visible damage at the end of the treatment period.

\section{Aphid settling test}

The objective was to test whether touch influences aphid settling on their host plants. An aphid no-choice settling test (Ninkovic et al. 2002) was used to investigate aphid behavioural response to touched and untouched plants. Both maize and bean plants were tested $24 \mathrm{~h}$ after the last touching treatment ended. The second maize leaf was placed inside a transparent $100-\mathrm{ml}$ polystyrene tube (diameter $2.5 \mathrm{~cm}$, length $25 \mathrm{~cm}$ ). For this test, the second leaf of each treatment plant placed inside the tube represented a replicate. Touched and untouched plants had 18 replicates, respectively. Ten wingless $R$. padi of second to fourth larval instars were placed inside the polystyrene tube. The upper end of the tube was sealed with nylon net, and the lower end was plugged with a plastic sponge through which the leaf entered via a slit. To minimise mechanical damage to the plants, the test tube was attached to a wooden stick to support the plant. The number of aphids settled on the leaf was recorded after $2 \mathrm{~h}$, which is sufficient time for aphids to settle and reach the phloem (Prado and Tjallingii 1997). Two parameters were used to evaluate whether aphids were settled on the leaf or not. The first parameter refers to slight leaf shaking during a period of approximately $10 \mathrm{~s}$, after removing the leaf from the tube. The second parameter suggested by Powell et al. (1993) was used for the aphids remaining on leaf. If the aphid body did not move and the antennae were in the heldback position without any movement, the aphid recorded as settled.

Due to the morphological differences of bean leaves, another no-choice settling test was done on a bean leaf that was placed in a Petri dish $(15 \times 2 \mathrm{~cm})$ through a side opening around the leaf petiole. The petiole was protected with a sponge prior to being placed in the Petri dish. Ten wingless $A$. fabae of second to fourth larval instars were placed into small tubes (diameter $5 \mathrm{~mm}$, length $4 \mathrm{~cm}$ ) and then carefully placed inside the Petri dish containing one bean leaf. The cover had a hole (diameter $6 \mathrm{~cm}$ ) protected with nylon net to prevent condensation. Bean leaves of touched and untouched plants were treated in the same way as described above. To avoid any plant disturbance, all Petri dishes were placed on a bench at the same height as the second leaves of the bean plants. As A. fabae spent more time walking before accepting the plant, the period for testing aphid settling was prolonged. Thus, after $3 \mathrm{~h}$, the number of aphids settled on the bean leaf was recorded using the same procedure as for $R$. padi. Aphid acceptance of bean leaves was tested on touched and control plants in 18 replicates. Data were expressed as a proportion of aphids settled on the leaves per tube/Petri dish.

Test of aphid olfactory response

The aim was to assess aphid olfactory preference when offered a choice between volatiles released by touched and untouched plants. Here, we tested olfactory preferences of $R$. padi for volatiles from touched and untouched maize plants and preferences of $A$. fabae for volatiles from touched and untouched bean plants. Olfactometry experiments were done $24 \mathrm{~h}$ after the last touching treatment. A twoway olfactometer was used, consisting of two stimulus arms (length $4 \mathrm{~cm}$ ) directly opposite each other, with a central zone $(2.5 \times 2.5 \mathrm{~cm})$ separating them.

Air was extracted from the centre of the olfactometer using a vacuum pump, establishing discrete air currents in the side arms. Airflow in the olfactometer was set to

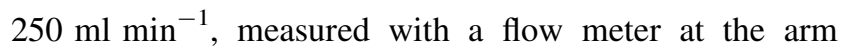
inlets. Touched and control plants were placed into separate, clean Perspex cages. One arm of each olfactometer was connected to a cage containing a touched plant and the other arm to a cage containing an untouched plant (Fig. 1). The position of the treatments in the two-arm olfactometer was switched between the left and right arms in each olfactometer to account for any positional bias.

Thirty minutes before each olfactometry experiment started, aphids were randomly chosen from cultures. One aphid of second to fourth instar was tested per olfactometer, and, after $10 \mathrm{~min}$ of acclimation, its position in the arena was registered 10 times at 3-min intervals (Ninkovic et al. 2009). Data were expressed as mean of individual aphid visits per olfactometer arm during the observation period of $30 \mathrm{~min}$. Observed positions of aphids in the middle part of olfactometer were excluded from the analyses. To prevent aphid visual responses, plants were surrounded by white paper cones (diameter $11 \mathrm{~cm}$ and height $15 \mathrm{~cm}$ ). The accumulated number of visits in the arm zones 
Fig. 1 Illustrative representation of the two-arm olfactometer connected to two Perspex cages (each $10 \times 10 \times 40 \mathrm{~cm}$, with an opening of $7 \mathrm{~cm}$ diameter in the front side) used to contain untouched (a) and touched (b) plants as odour sources. Arrows show airflow direction through the system

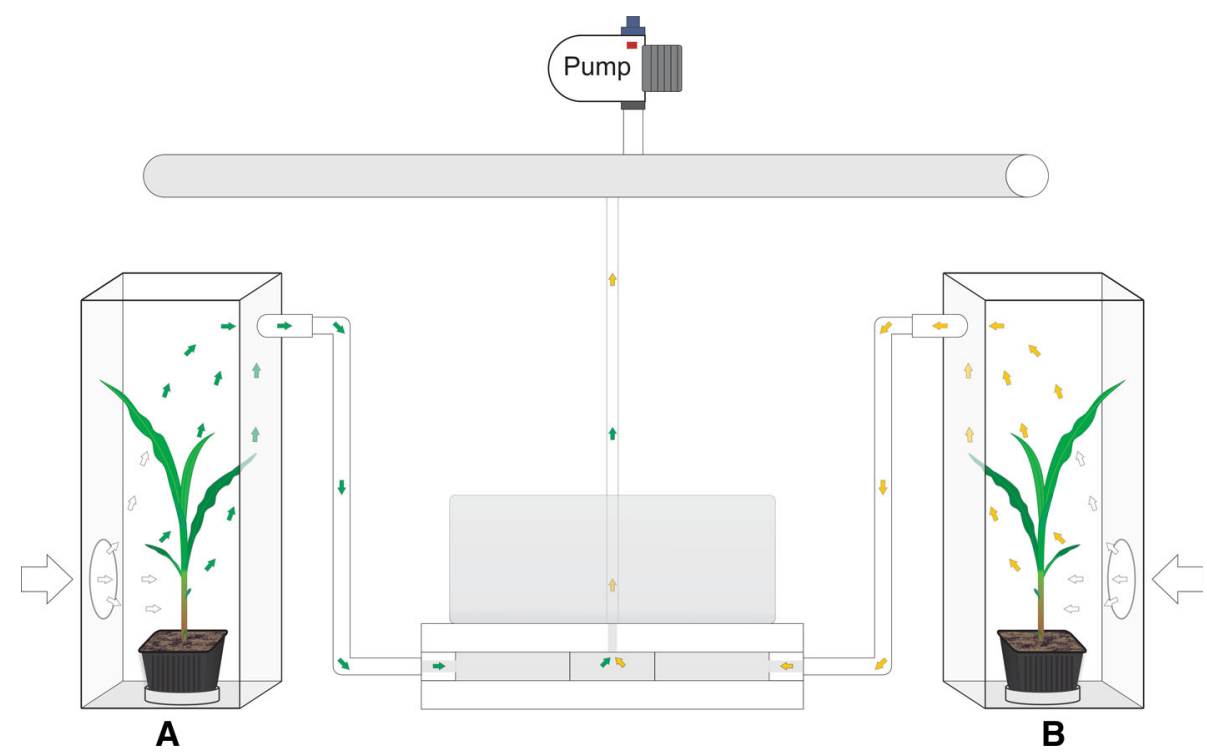

after ten recordings was regarded as one observation. If an aphid did not move between three consecutive observations (was motionless), the replicate was discarded and a new one started with a new insect. The experiments were replicated with 16 individuals of $A$. fabae, giving them the choice between the odour of touched and untouched bean plants, and with 26 individuals of $R$. padi, with choice between the odour of touched and untouched maize plants. Each individual aphid was used only once. To avoid contamination between replicates, all olfactometers were cleaned between each trial.

\section{Test of ladybird olfactory response}

The olfactory preference of $C$. septempunctata males and females to volatiles from touched and untouched maize and bean plants was tested using a two-arm olfactometer consisting of an arena $(6 \times 6 \mathrm{~cm})$ with two conical, extended arms (arm length $7 \mathrm{~cm}$ ) (Ninkovic et al. 2001; Glinwood et al. 2009) with an airflow of $250 \mathrm{ml} \mathrm{min}^{-1}$. Ladybirds were randomly collected from culture $24 \mathrm{~h}$ before each experiment and separated by sex according to Baungaard (1980). During the 24-h period, males and females were kept in separate clean jars covered with net, without access to food and provided with a L16:D8 light cycle. Water was provided in a glass tube plugged with cotton wool. Tested plants were placed into clear Perspex cages and connected to the side arms of the olfactometer. An adult ladybird was placed in the central zone of the olfactometer and, after a 10-min acclimation period, its position was registered 10 times at 2-min intervals. The 2-min intervals are long enough to permit an adult ladybird to move from one end of the arena to the other (Ninkovic et al. 2001). For this purpose, 22 and 27 male and female ladybirds, respectively, were tested. Observations were done in the same way as described for aphids. For each ladybird tested, a new clean olfactometer was used.

Plant response to touching

Maize and bean plants were cut at a ground level using scissors and separated into stem, leaves and roots. Roots from each plant were washed carefully with water. Stem and leaves were scanned for each plant separately using a dual lens scanner (Epson 4490Pro). Leaf surface and stem height were calculated using WinRHIZO (Regent Instruments), an image analysis system specifically designed for plant morphological measurements. Leaves, stem and roots from each plant were separately packed into labelled aluminium bags. After drying for $48 \mathrm{~h}$ at $70{ }^{\circ} \mathrm{C}$ to constant mass dry weights, plants spent $24 \mathrm{~h}$ at room temperature and were then weighed. These data were used for the calculation of integral morphological indices specific leaf area (SLA) and shoot root ratio (S/R). SLA is calculated as ratio of leaf area to dry weight while $S / R$ as ratio of shoots dry mass (leaf plus stem) to root dry mass.

Collection of volatiles

Prior to volatile collection, polyethyleneterephthalate (PET) oven bags $\left(35 \mathrm{~cm} \times 43 \mathrm{~cm}\right.$, Toppits ${ }^{\circledR}$, Klippan, Sweden) were baked in an oven at $140{ }^{\circ} \mathrm{C}$ for $2 \mathrm{~h}$ to remove contaminants. Glass tubes $(5 \mathrm{~mm}$ diameter) containing Tenax TA (Supelco, Bellefonte PA, USA; 60/80 mesh, $50 \mathrm{mg}$ ) were heated at $220{ }^{\circ} \mathrm{C}$ under nitrogen for $2 \mathrm{~h}$ to remove contaminants. Plants were subjected to brushing treatment as described above, and control plants were untreated. Twenty-four hours after this treatment, pots 
containing either one maize plant or one bean plant were carefully enclosed in oven bags, taking care not to touch the leaves and shoots. Charcoal-filtered air was pumped in at $400 \mathrm{ml} \mathrm{min}^{-1}$, and a tube containing Tenax was inserted through a hole in the top of the bag and air drawn through via PTFE tubing connected to a pump $\left(300 \mathrm{ml} \mathrm{min}^{-1}\right)$. The difference in flow rates created a positive pressure to ensure no air from the laboratory entered the system. A small hole cut in the top of the bag prevented build-up of pressure. Air was pumped in for 30 min prior to volatile collection to flush contaminating volatiles from the system.

Volatile collection was carried out for $48 \mathrm{~h}$ under controlled environmental conditions $\left(22{ }^{\circ} \mathrm{C}, 16 \mathrm{~h}: 8 \mathrm{~h}\right.$ lightdark cycle). Seven replicates were carried out for each treatment, and two control treatments consisting of pots and soil without plants were included.

Chemical analysis

Volatiles were analysed by gas chromatography-mass spectrometry (GC/MS) on an Agilent 7890N (Agilent Technologies) GC coupled to an Agilent 5975C mass selective detector (electron impact $70 \mathrm{eV}$ ). The $\mathrm{GC}$ was equipped with an HP-1 column (100\% dimethyl polysiloxane, $30 \mathrm{~m}, 0.25 \mathrm{~mm}$ i.d. and $0.25 \mu \mathrm{m}$ film thickness, J\&W Scientific, USA) and fitted with an Optic 3 thermal desorption system (Atas GL Intl., Veldhoven, Netherlands). The liner containing the Tenax with absorbed volatiles was placed directly into the injector, and volatiles were thermally desorbed starting at $30{ }^{\circ} \mathrm{C} / 0.5 \mathrm{~min}$ and rising at $30{ }^{\circ} \mathrm{C} / \mathrm{s}$ to $250{ }^{\circ} \mathrm{C}$. The $\mathrm{GC}$ temperature programme was $30{ }^{\circ} \mathrm{C} / 2 \mathrm{~min}, 5{ }^{\circ} \mathrm{C} / \mathrm{min}$ to $150{ }^{\circ} \mathrm{C} / 0.1 \mathrm{~min}$, $10{ }^{\circ} \mathrm{C} / \mathrm{min}$ to $250{ }^{\circ} \mathrm{C} / 15 \mathrm{~min}$, using Helium as carrier with a flow rate of $1.3 \mathrm{ml} / \mathrm{min}$. Volatile compounds were identified by comparison against a commercially available library (NIST 08) and by comparison of mass spectra and retention indices with commercially available authentic standards where available. Only compounds appearing in the headspace of plants and not pots with soil were quantified. Most of the compounds identified have been previously reported from $Z$. mays (Degen et al. 2004) and $P$. vulgaris (Wei et al. 2006).

Compounds were quantified using three-point response curves constructed using authentic standards where available. No authentic standards were available for $\alpha$-bergamotene or the unknown sesquiterpenes, and these substances were quantified using the sesquiterpene $(E)-\beta$ caryophyllene. Chemical standards were obtained commercially as follows: (Z)-3-hexen-1-ol (Sigma-Aldrich $98 \%$ ), 6-methyl-5-hepten-2-one (Sigma-Aldrich $99 \%$ ), $\beta$ myrcene (Fluka 90\%), (Z)-3-hexenyl acetate (SigmaAldrich $98 \%$ ), linalool oxide (Fluka $>97 \%$ ), linalool (Sigma-Aldrich $97 \%$ ), indole (Sigma-Aldrich $>99 \%$ ), (+)-cyclosativene (Sigma-Aldrich $99 \%$ ), $\beta$-caryophyllene $($ Fluka $>98.5 \%),(E)$ - $\beta$-farnesene (Fluka $>90 \%),(+)$ valencene (Sigma-Aldrich $>70 \%$ ), $\beta$-bisabolene (Alfa Aesar) and $(E)$-nerolidol (Fluka $>85 \%$ ). Standards of $(E)$ ocimene, $(E, E)-4,8,12$-Trimethyl-1,3,7,11-tridecatetraene (TMTT) and (E)-4,8-dimethyl-1,3,7-nonatriene (DMNT) were kindly provided by Dr Mike Birkett, Rothamsted Research, UK.

\section{Statistical analysis}

Aphid acceptance was obtained in the form of proportions, and data were modelled using a generalised linear mixed model (e.g., Littell et al. 2006). In such models, data can take distributions other than normal, and the form of the relationship can be modelled through a link function. The following specifications were included in the model: the proportion of aphids settling in each tube/Petri dish was modelled using a binomial distribution, the logit link was used, the fixed part of the model included touch treatment (touched and untouched plants of maize and bean) and block, whereas the block $\times$ treatment interaction was regarded as a random factor. The hypothesis of no difference between treatments was tested at the $5 \%$ level. Pairwise comparisons between least-square means were calculated and compared using Tukey's HSD test. Proc GLIMMIX of the SAS Institute (2011) package was used.

Data from olfactory bioassays were analysed with Wilcoxon's matched pairs tests. Differences in morphological parameters between touched and untouched plants were tested by $t$ test. These analyses were performed with the Statistica software (Statsoft Inc. 2011).

One-way ANOVA (see e.g., Olsson 2011) was used to analyse whether any of the volatiles was related to treatment. Stepwise discriminant analysis (see e.g., Johnson and Wichern 2007) was used to conclude test any combination of volatiles could detect whether the plant was treated or not.

\section{Results}

Does plant touch response have an influence on aphid host plant acceptance?

The results summarised in Fig. 2 show changes in aphid host acceptance by $R$. padi on maize leaves and by A. fabae on bean leaves. Significant differences between treatments were found $\left(\mathrm{F}_{3,49}=14.55, P<0.0001\right)$, but there were no significant differences between blocks $\left(\mathrm{F}_{17,49}=0.74\right.$, $P=0.75$ ). Significantly lower settling by $R$. padi was observed on touched maize leaves than on untouched maize leaves ( $P=0.047$, Tukey's HSD test) (Fig. 2a). A similar reduction in settling by $A$. fabae was found on 

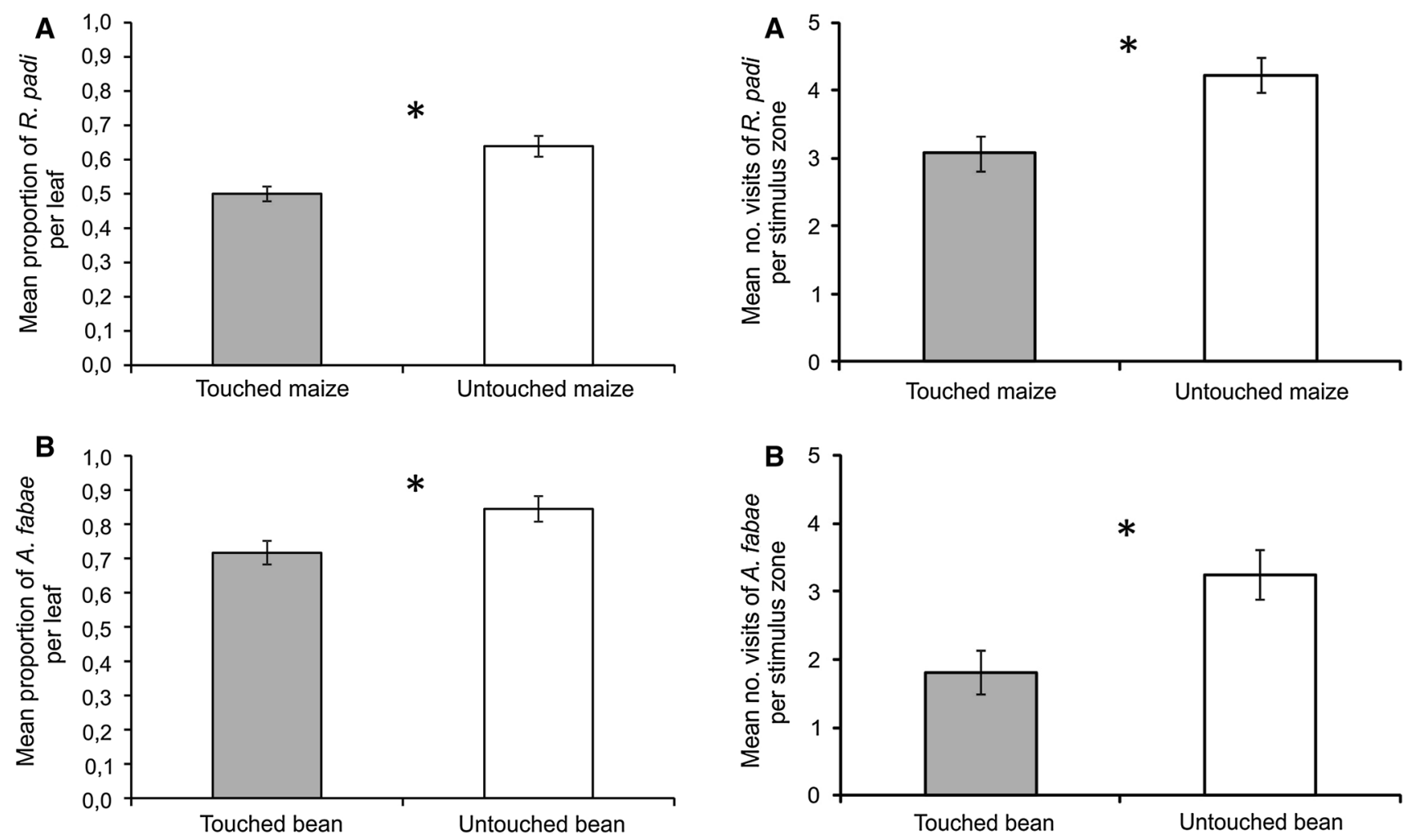

Fig. 2 Aphid settling test on touched and untouched leaves. Graphs show data on plant basis, bar graphs represent an average of aphid settling in no-choice test \pm SE. a $R$. padi on maize leaves, $\mathbf{b}$ A. fabae on bean leaves. Significant differences in aphid settling on touched and untouched plants are indicated (Tukey's test HSD; $* P<0.05$ )

touched bean leaves compared with untouched bean leaves ( $P=0.041$, Tukey's HSD test) (Fig. $2 b)$. These results show that touching may induce responses in both plant species tested, reducing host plant attractiveness for aphids.

\section{Aphid olfactory response}

Does plant touching change aphid olfactory preferences?

Rhopalosiphum padi had significantly lower preference for volatiles released from previously touched maize plants compared with volatiles from untouched plants (Wilcoxon's test, $T=59.0 ; N=26 ; P=0.028$ ) (Fig. 3a). The same response to volatiles from touched bean plants was observed with A. fabae (Wilcoxon's test, $T=13.0 ; \quad N=16$; $P=0.023$ ) (Fig. 3b). Both plant species exposed to touching changed their volatile emission in a way that reduced aphid host plant preferences.

How do ladybirds respond to odours released from touched plants?

Significantly reduced attracting/arresting effects on walking behaviour of ladybirds of both sexes were apparent in

Fig. 3 Aphid olfactory response to volatiles from touched and untouched plants. Bar graphs represent an average of aphid visits per olfactometer arm \pm SE. a $R$. padi olfactory response to odours from touched and untouched maize plants, $\mathbf{b} A$. fabae olfactory response to odours from touched and untouched bean plants. Significant differences in aphid olfactory response are indicated (Wilcoxon's mean pairs test; $* P<0.05$ )

response to the odours of touched maize plants compared with the odours of untouched maize plants (females Wilcoxon's test $T=54.5 ; N=27 ; P=0.02$ and males Wilcoxon's test $T=43.0 ; N=23 ; P=0.02$ ) (Fig. 4). A similar pattern was observed when ladybirds were given the choice between odours from touched and untouched bean plants. The volatiles from touched plants were significantly less attractive to ladybird females (Wilcoxon's test, $T=48.0 ; N=23 ; P=0.03$ ) and males (Wilcoxon's test, $T=25.0 ; N=22 ; P=0.01)$ than volatiles from untouched bean plants (Fig. 5).

Touch-induced morphological changes in plants

The effects of touch on plant morphology are summarised in Table 1 for maize and in Table 2 for bean. Touched maize plants showed significant reduction in all tested parameters in comparison with control except root biomass. Bean plants responded to touch by increase in leaf weight, leaf surface and total biomass. Significant reduction in stem height and SLA was observed as a common respond to touch in both plant species. 

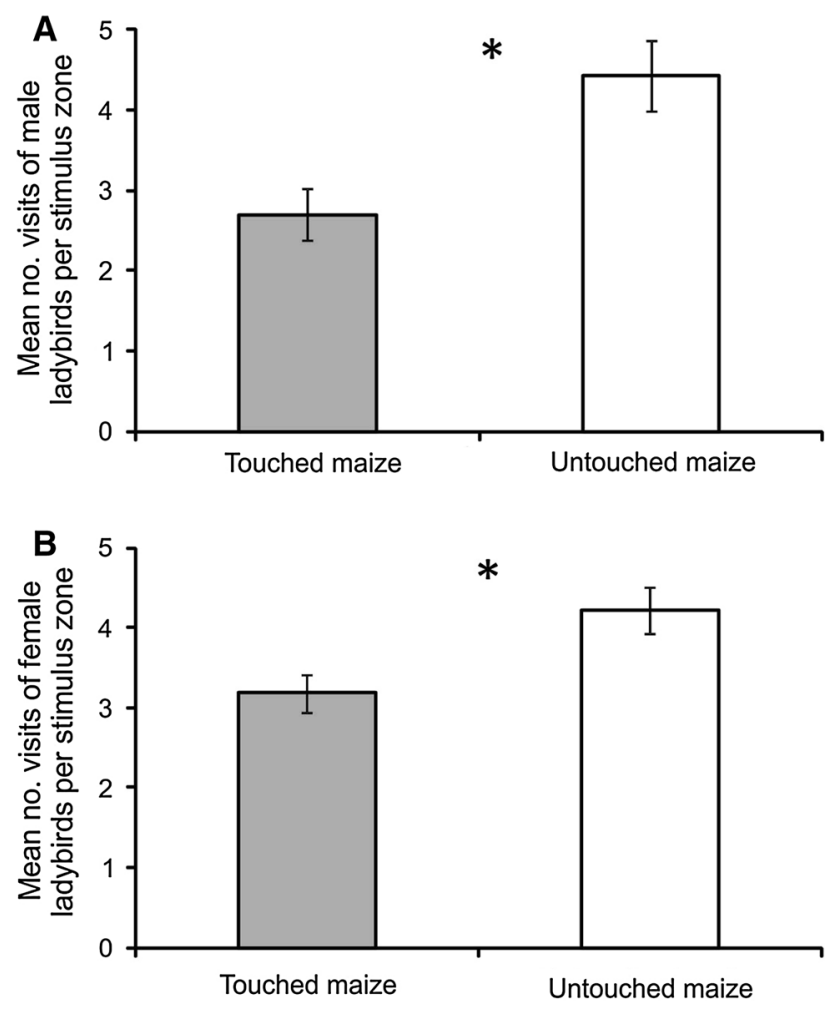

Fig. 4 Olfactory preferences of male (a) and female (b) ladybirds for odours from touched and untouched maize plants. Significant differences in ladybirds' olfactory response are indicated (Wilcoxon's mean pairs test; ${ }^{*} P<0.05$ )

\section{Volatile profiles of touched plants}

Differences in compounds identified at headspace collection from touched and untouched maize and bean plants are shown in Figs. 6 and 7, respectively. Discriminant analysis was used to identify combinations of variables that optimally differentiate between the treatments. The model with only two variables correctly identified the treatment for all 14 Bean plants and for 11 out of 14 Maize plants. Stepwise discriminant analyses of headspace of touched and untouched maize plants identified $(E)$-nerolidol $(P=0.0112)$ and $\beta$-caryophyllene $(P=0.0076)$ as compounds that were associated with touching treatment. The same analyses for bean identified 6-methyl-5-hepten-2-one $(P=0.0106)$ and an unidentified sesquiterpene as compounds associated with touching.

\section{Discussion}

Our study shows that 1 min leaf touching per day over a period of 6 days with a soft face brush can have considerable effects on searching behaviour of aphids and their most common natural enemy, ladybirds. This short period of gentle plant touching was sufficient to induce a plant
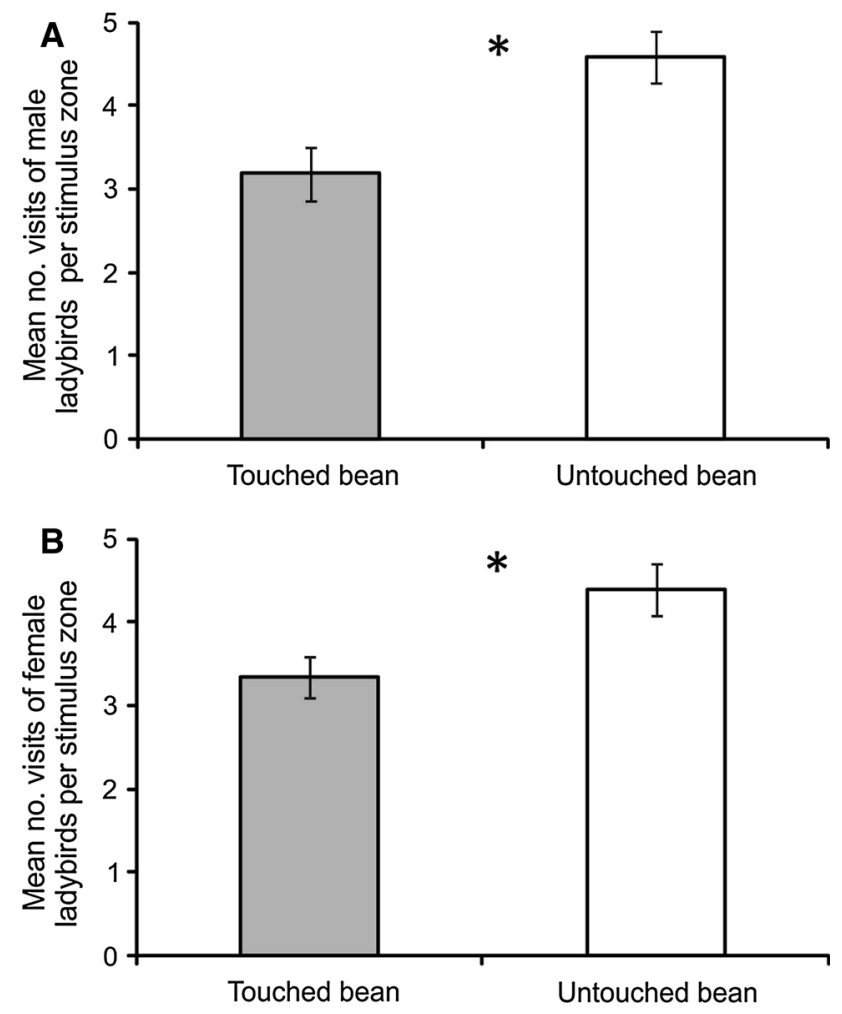

Fig. 5 Olfactory preferences of male a and female b ladybirds for odours from touched and untouched bean plants. Significant differences in ladybirds' olfactory response are indicated (Wilcoxon's mean pairs test; $* P<0.05$ )

response that significantly reduced host plant acceptance for common aphid pest species on maize and bean. The aphid response may prolong the search for an optimal feeding site, which in turn may have negative implications for aphid reproduction and population development on their host plants (Van Emden et al. 1990; Moran and Cipollini 1999). Plant responses to mechano stimuli also affected ladybirds, which preferred volatiles from untouched plants over those from touched plants. Therefore, plant responses to touch may have implications for organisms at higher trophic levels. To our knowledge, this is the first report showing that changes in plants induced by touch can affect aphids and ladybirds.

Touching by other leaves within dense canopies can often be elicited by more common environmental factors such as wind and rain (Braam and Davis 1990; Cipollini 1997). Even the gentle touch of insects on trichomes on the leaf surface may activate plant defences against herbivores (Shepherd and Wagner 2007; Peiffer et al. 2009). Pest pressure reduction from the two-spotted spider mite and thrips was observed after brushing marigold and ageratum plants grown in a greenhouse (Latimer and Oetting 1999). Phytochemical responses in plants caused by wounding can also be activated by touching and lead to increased insect 
Table 1 Effect of 1 min leaf touching over a period of 6 days on morphological characteristics of maize plants

$t$ values are from $t$ test, \pm is standard error

Table 2 Effect of 1 min leaf touching over a period of 6 days on morphological characteristics of bean plants

$t$ values are from $t$ test, \pm is standard error

\begin{tabular}{lcccc}
\hline & $\begin{array}{c}\text { Touched plants } \\
\text { (Mean } \pm \mathrm{SE})\end{array}$ & $\begin{array}{c}\text { Untouched plants } \\
(\text { Mean } \pm \mathrm{SE})\end{array}$ & $t$ value & $P$ value \\
\hline Stem height $(\mathrm{cm})$ & $15.39 \pm 0.27$ & $17.53 \pm 0.23$ & 5.95 & $<0.0001$ \\
Total plant biomass $(\mathrm{g})$ & $0.38 \pm 0.01$ & $0.43 \pm 0.01$ & 3.72 & 0.0007 \\
Root weight $(\mathrm{g})$ & $0.08 \pm 0.002$ & $0.08 \pm 0.003$ & 0.10 & 0.92 \\
Stem weight $(\mathrm{g})$ & $0.11 \pm 0.003$ & $0.13 \pm 0.004$ & 4.44 & $<0.0001$ \\
Leaf weight $(\mathrm{g})$ & $0.19 \pm 0.006$ & $0.22 \pm 0.006$ & 3.50 & 0.001 \\
Leaf surface $\left(\mathrm{cm}^{2}\right)$ & $90.04 \pm 3.14$ & $114.11 \pm 3.43$ & 5.17 & $<0.0001$ \\
SLA $\left(\mathrm{cm}^{2} \mathrm{~g}^{-1}\right)$ & $475.67 \pm 5.12$ & $517.86 \pm 4.88$ & 5.96 & $<0.0001$ \\
S/R & $3.66 \pm 0.13$ & $4.41 \pm 0.2$ & 3.11 & 0.004 \\
\hline
\end{tabular}

\begin{tabular}{lcccc}
\hline & $\begin{array}{c}\text { Touched plants } \\
\text { (Mean } \pm \mathrm{SE})\end{array}$ & $\begin{array}{c}\text { Untouched plants } \\
(\text { Mean } \pm \mathrm{SE})\end{array}$ & $t$ value & $P$ value \\
\hline Stem height $(\mathrm{cm})$ & $11.79 \pm 0.17$ & $12.52 \pm 0.29$ & -2.18 & 0.04 \\
Total plant biomass $(\mathrm{g})$ & $0.69 \pm 0.02$ & $0.59 \pm 0.02$ & 3.76 & 0.001 \\
Root weight $(\mathrm{g})$ & $0.12 \pm 0.006$ & $0.10 \pm 0.004$ & 3.04 & 0.004 \\
Stem weight $(\mathrm{g})$ & $0.09 \pm 0.002$ & $0.08 \pm 0.003$ & 2.70 & 0.10 \\
Leaf weight $(\mathrm{g})$ & $0.47 \pm 0.09$ & $0.41 \pm 0.13$ & 3.65 & 0.001 \\
Leaf surface $\left(\mathrm{cm}^{2}\right)$ & $230.24 \pm 5.25$ & $235.81 \pm 5.81$ & -0.71 & 0.48 \\
SLA $\left(\mathrm{cm}^{2} \mathrm{~g}^{-1}\right)$ & $486.17 \pm 6.63$ & $571.66 \pm 6.26$ & -9.38 & $<0.0001$ \\
S/R & $4.91 \pm 0.20$ & $5.23 \pm 0.20$ & -1.13 & 0.27 \\
\hline
\end{tabular}

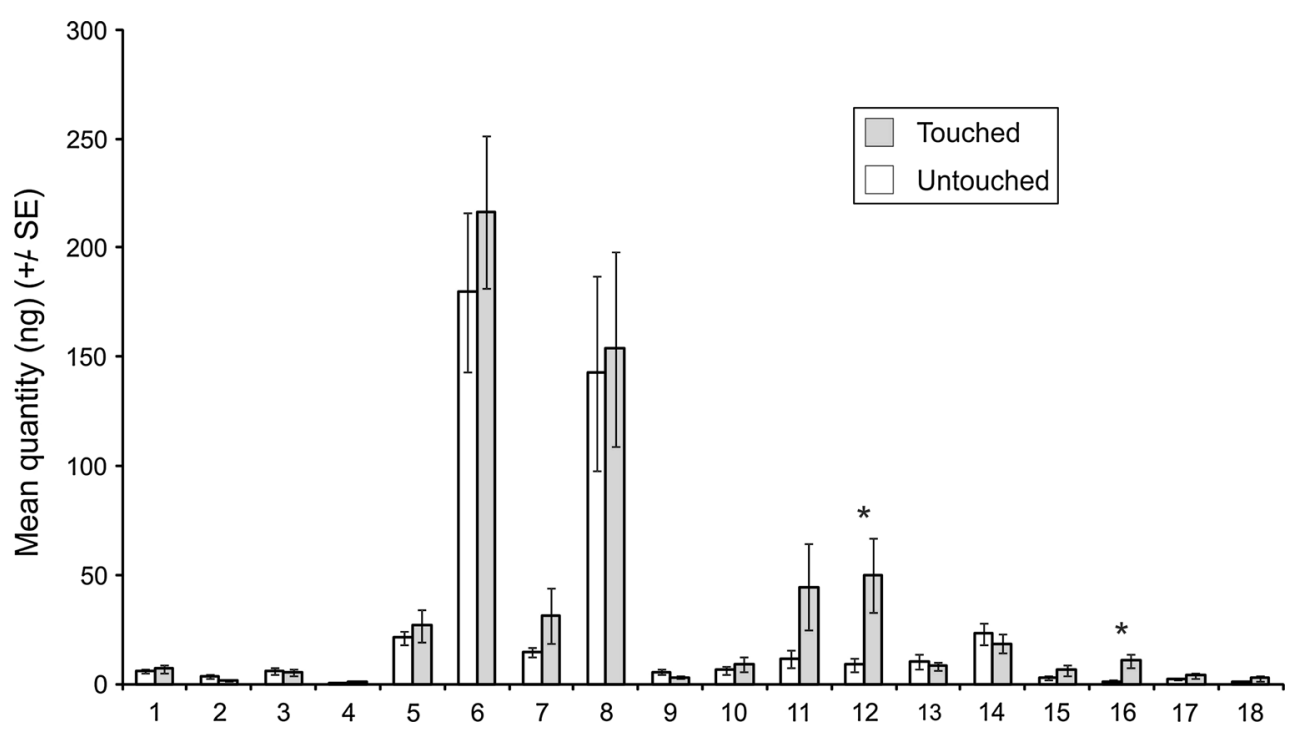

Fig. 6 Mean quantities ( $\mathrm{ng} \pm \mathrm{SE}$ ) of volatile organic compounds identified from the headspace of touched and untouched maize plants. Compound numbers: 1 (Z)-3-hexen-1-ol; $2 \beta$-myrcene; 3 (Z)-3hexenyl acetate; $4(E)$-ocimene; 5 linalool oxide; 6 linalool; $7(E)-4,8$ dimethyl-1,3,7-nonatriene; 8 indole; $9(+)$-cyclosativene; $10 \beta$ -

resistance (Smith 1988). Recent reviews have documented that most plants possess the ability to perceive and respond to touch (Braam 2005; Telewski 2006) by morphological (Liu et al. 2007) and physiological adjustments (Chehab caryophyllene; $11 \alpha$-bergamotene; $12(E)$ - $\beta$-farnesene; 13 unknown sesquiterpene 1; $14(+)$-valencene; $15 \beta$-bisabolene; $16(E)$-nerolidol; $17(E, E)-4,8,12$-Trimethyl-1,3,7,11-tridecatetraene; and 18 unknown sesquiterpene 2. $* P<0.05$ One-way ANOVA

et al. 2012). Touched maize plants in our study exhibited significant reductions in all tested morphological parameters except root weight (see Table 1.) which is in line with previous studies (Montgomery et al. 2004; Liu et al. 2007; 
Fig. 7 Mean quantities (ng $\pm \mathrm{SE}$ ) of volatile organic compounds identified from the headspace of touched and untouched bean plants. Compound numbers: 1 6-methyl-5-hepten-2-one; 2 (Z)3-hexenyl acetate; $3(E)$ - $\beta$ ocimene; 4 linalool oxide; 5 linalool; $6(E)$-4,8-dimethyl1,3,7-nonatriene; $7 \beta$ caryophyllene; $8 \alpha$ bergamotene; 9 unknown sesquiterpene $1 ; 10(E, E)$ 4,8,12-Trimethyl-1,3,7,11tridecatetraene; and 11 unknown sesquiterpene 2 . $* P<0.05$ One-way ANOVA

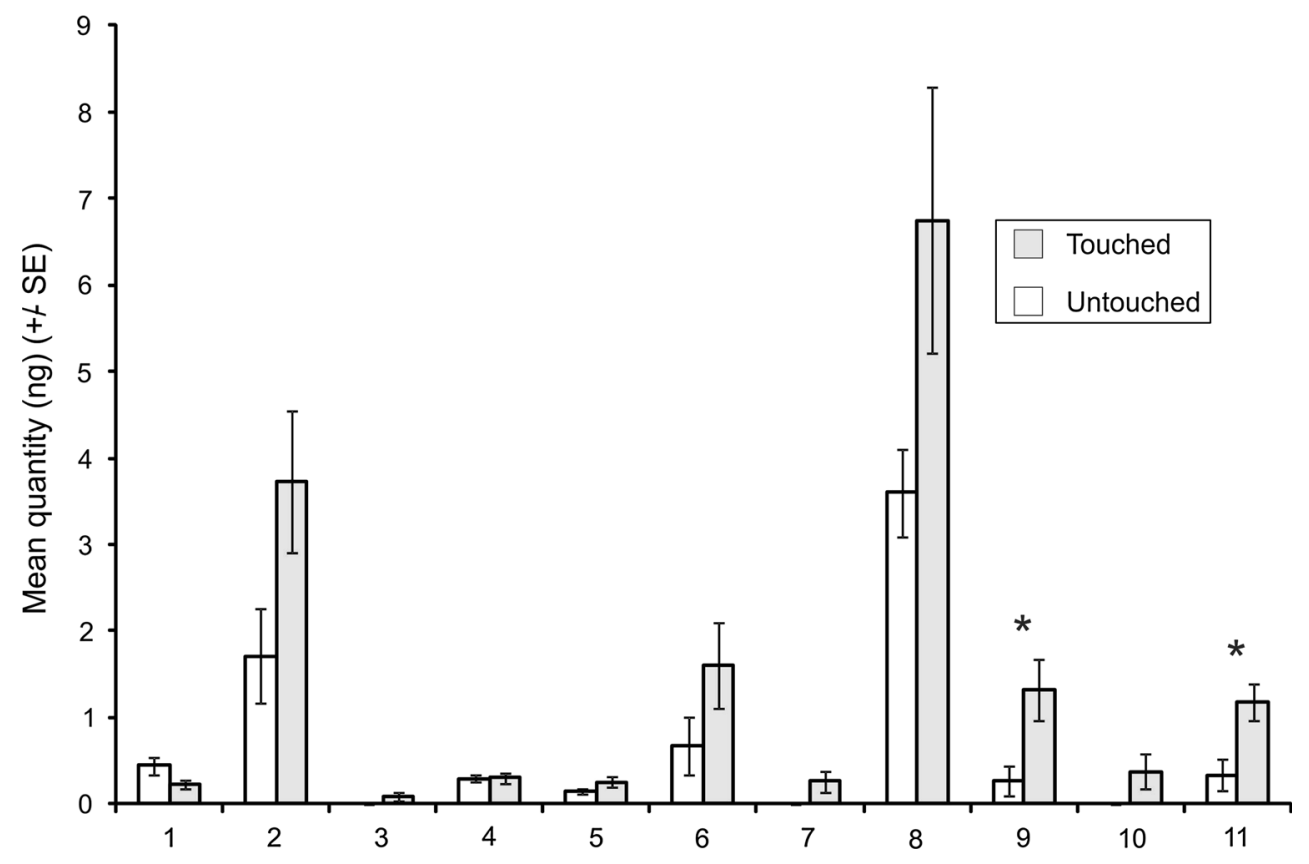

Anten et al. 2010). Bean plants responded to touch by increase in total plant biomass (see Table 2), which was also found by Tretner et al. (2008). Significantly lower SLA and stem height in both plant species indicate the occurrence of certain qualitative and quantitative changes in plant volatile emission as a result of alternations in leaf morphology and physiology.

Plant physiological changes induced by touching may induce the synthesis of an array of signalling substances (Braam 2005) that may play an important role in aphid host location and selection. Our results shows that touch can significantly alter the volatile profile in both plant species. The stepwise statistical procedure for maize plants indicated that the sesquiterpenes $(E)$-nerolidol and $(E)-\beta$ caryophyllene were the compounds that best discriminated the volatile blend of touched plants from that of untouched plants. Previous studies have illustrated that these compounds can significantly reduce aphid performance and settling on plants (Hijaz et al. 2013; Ninkovic et al. 2013). $(E)$ - $\beta$-caryophyllene has also been identified as a volatile involved in plant defence against other sucking insects (Oluwafemi et al. 2013). For bean, the discriminant analysis indicated that an unidentified sesquiterpene and 6-methyl-5-hepten-2-one make a significant contribution to the changed volatile profile of touched plants. 6-methyl-5hepten-2-one has been previously shown to repel aphids from aphid-infested cereal plants (Quiroz et al. 1997). It is known that $(E)$ - $\beta$-caryophyllene can mask other chemical compounds and induce avoidance behaviour in ladybirds (Al Abassi et al. 2000). Thus, there were specific changes in volatile profile associated with touching in both plants. Further experiments are needed to establish whether the changes in emissions of singe volatile compounds or the volatile blend are responsible for the effects on aphid and ladybird behaviour.

The reduced aphid acceptance of touched plants could most likely be explained by the aphids' ability to quickly detect physiological changes in host plants. Activation of an early touch detection system in plants can be valuable if a defence is activated before herbivore arrival. Chehab et al. (2012) proposed that mechanically stimulated plants may be primed for a defence manifesting enhanced resistance to pests. This may represent an advantage for touched plants to partially repel aphids and thus reduce potential feeding damage.

During the process of plant acceptance, aphids use different cues to evaluate host plant quality whereby volatile and contact chemical cues can be crucial to an aphid's decision to settle on a plant (Webster 2012). Aphid antennae are able to detect a large number of odours due to the presence of receptor proteins that are extremely sensitive to the specific odours they perceive (Rützler and Zwiebel 2005). Equipped with such highly sensitive antennae, aphids are able to detect even the smallest changes in the volatile profile of their host plants (Pare and Tumlinson 1999). A significant reduction in attractiveness towards volatiles released by briefly touched plants may cause aphids to spend more time in search of other suitable host plants or feeding sites, exposing them to a greater risk of predation. Plant touching as a ubiquitous phenomenon could have a more pronounced effect on pests in environments where the plants are exposed to mechanical components of wind/rain at higher intensities and for longer durations. Long-term plant exposure to mechanical stress 
significantly decreases aphid reproduction ranging from $17 \%$ after 1 week to $35 \%$ after 3 weeks (Van Emden et al. 1990). However, it is unknown whether all plant species can respond to touch in the same way and how long the response will persist after stimulation under different environmental conditions.

Due to the important role of olfactory cues in the foraging behaviour of many herbivore natural enemies, plant chemical cues provide an important route for direct interaction between the first and third trophic levels (Dicke et al. 2003). Volatile cues associated with specific host plants or habitats may have a decisive role in ladybird foraging behaviour (Pettersson et al. 2005). Early in the season, ladybirds can arrive in crops before aphid migrants and, for this purpose, they use plant volatile chemicals (Honěk and Martinková 2008; Ninkovic and Pettersson 2003; Ninkovic et al. 2011). The current study demonstrates that touch can induce changes in the emission of plant volatiles and can affect ladybird searching behaviour, suggesting a preference for less stressed plants. Therefore, changes in plant status induced by touching may affect the foraging behaviour of both aphid species and an important natural enemy, ladybirds. The link between plant touching and insect behaviour identified in our study represents a new phenomenon that contributes to the broader ecological significance of induced plant responses to biotic stress.

Acknowledgments The study was financially supported by the Fund Rajko and Maj Djermanovic and the Swedish Foundation for Strategic Environmental Research (MISTRA) through the PlantComMistra programme. The authors thank Annhild Andersson, Iris Dahlin and Erika Qvarfordt for skilled technical assistance.

Open Access This article is distributed under the terms of the Creative Commons Attribution License which permits any use, distribution, and reproduction in any medium, provided the original author(s) and the source are credited.

\section{References}

Al Abassi S, Birkett MA, Pettersson J, Pickett JA, Wadhams LJ, Woodcock CM (2000) Response of the sevenspot ladybird to an aphid alarm pheromone and an alarm pheromone inhibitor is mediated by paired olfactory cells. J Chem Ecol 26: $1765-1771$

Anten NPR, Alcala-Herrera R, Schieving F, Onoda Y (2010) Wind and mechanical stimuli differentially affect leaf traits in Plantago major. New Phytol 188:554-564. doi:10.1111/j.14698137.2010.03379.x

Baungaard J (1980) A simple method for sexing Coccinella septempunctata (Coleoptera: Coccinellidae). Entomol Medd 48:26-28

Braam J (2005) In touch: plant responses to mechanical stimuli. New Phytol 165:373-389. doi:10.1111/j.1469-8137.2004.01263.x

Braam J, Davis RW (1990) Rain-, wind-, and touch-induced expression of calmodulin and calmodulin-related genes in Arabidopsis. Cell 60:357-364. doi:10.1016/0092-8674(90)90587-5
Cahill JF, Castelli JP, Casper BB (2001) The herbivory uncertainty principle: visiting plants can alter herbivory. Ecology 82:307-312. doi:10.1890/0012-9658(2001)082[0307:THUPVP]2.0.CO;2

Chehab W, Yao C, Henderson Z, Kim S, Braam J (2012) Arabidopsis touch-induced morphogenesis is jasmonate mediated and protects against pests. Curr Biol 22:701-706. doi:10.1016/j.cub.2012.02.061

Cipollini DF (1997) Wind-induced mechanical stimulation increases pest resistance in common bean. Oecologia 111:84-90

Degen T, Dillmann C, Marion-Poll F, Turlings TCJ (2004) High genetic variability of herbivore-induced volatile emission within a broad range of maize inbred lines. Plant Physiol 135:1928-1938

Dicke M, van Poecke RMP, de Boer JG (2003) Inducible indirect defence of plants: from mechanisms to ecological functions. Basic Appl Ecol 4:27-42. doi:10.1078/1439-1791-00131

Forterre Y, Skotheim JM, Dumais J, Mahadevan L (2005) How the Venus flytrap snaps. Nature 433:421-425. doi:10.1038/nature03185

Glinwood R, Ahmed E, Qvarfordt E, Ninkovic V, Pettersson J (2009) Airborne interactions between undamaged plants of different cultivars affect insect herbivores and natural enemies. Arthropod Plant Interact 3:219-224. doi:10.1007/s11829-009-9072-9

Hijaz F, El Shesheny I, Killiny N (2013) Herbivory by the insect Diaphorina citri induces greater change in citrus plant volatile profile than does infection by the bacterium. Candidatus Liberibacter asiaticus. Plant Signal Behav 8:e25677

Honěk A, Martinková Z (2008) Why is Coccinella septempunctata so successful (a point of view). Eur J Entomol 105:1-12

Jaffe MJ (1973) Thigmomorphogenesis: the response of plant growth and development to mechanical stimulation. Planta 114:143-157. doi:10.1007/BF00387472

Johnson RichardA, Wichern DeanW (2007) Applied multivariate statistical analysis, 6th edn. Pearson Education, Upper Saddle River, NJ

Latimer JG, Oetting RD (1999) Conditioning treatments affect insect and mite populations on bedding plants in the greenhouse. HortScience 34(2):235-238

Littell RC, Milliken GA, Stroup WW, Wolfinger R, Schonberrger O (2006) SAS for mixed models, 2nd edn. SAS Institute, Cary, NC

Liu Y, Schieving F, Stuefer JF, Anten NPR (2007) The effects of mechanical stress and spectral shading on the growth and allocation of ten genotypes of a stoloniferous plant. Ann Bot 99:121-130. doi:10.1093/aob/mcl230

Montgomery JA, Bressan RA, Mitchell CA (2004) Optimizing environmental conditions for mass application of mechano-dwarfing stimuli to Arabidopsis. J Am Soc Hortic Sci 129(3):339-343

Moran PJ, Cipollini DF (1999) Effect of wind-induced mechanical stress on soluble peroxidase activity and resistance to pest in cucumber. J Phytopathol 147:313-316

Ninkovic V, Pettersson J (2003) Searching behaviour of the seven spotted ladybird, Coccinella septempunctata-effects of plantplant odour interaction. Oikos 100:65-70. doi:10.1034/j.16000706.2003.11994.x

Ninkovic V, Al Abbasi S, Pettersson J (2001) The influence of aphid induced plant volatiles on ladybird beetle searching behaviour. Biol Control 21:191-195. doi:10.1006/bcon.2001.0935

Ninkovic V, Olsson U, Pettersson J (2002) Mixing barley cultivars affects aphid host plant acceptance in field experiments. Entomol Exp Appl 102:177-182. doi:10.1046/j.1570-7458. 2002.00937.x

Ninkovic V, Glinwood R, Dahlin I (2009) Weed-barley interactions affect plant acceptance by aphids in laboratory and field experiments. Entomol Exp Appl 133:38-45. doi:10.1111/j. 1570-7458.2009.00900.x

Ninkovic V, Al Abassi S, Ahmed E, Glinwood R, Pettersson J (2011) Effect of within-species plant genotype mixing on habitat preference of a polyphagous insect predator. Oecologia 166:391-400. doi:10.1007/s00442-010-1839-2 
Ninkovic V, Dahlin I, Vucetic A, Petrovic-Obradovic O, Glinwood R, Webster B (2013) Volatile exchange between undamaged plants-a new mechanism affecting insect orientation in intercropping. PLoS ONE 8(7):1-9. doi:10.1371/journal.pone. 0069431

Olsson, Ulf (2011) Statistics for life science 1. Lund, Studentlitteratur SAS Institute Inc. (2012): SAS/Stat User's Guide. Version 9.3. SAS Institute Inc., Cary, NC

Oluwafemi S, Dewhirst SY, Veyrat N, Powers S, Bruce TJA et al (2013) Priming of production in maize of volatile organic defence compounds by the natural plant activator cis-jasmone. PLoS ONE 8(6):e62299. doi:10.1371/journal.pone.0062299

Pare PW, Tumlinson JH (1999) Plant volatiles as a defense against insect herbivores. Plant Physiol 121:325-331. doi:10.1104/pp. 121.2.325

Peiffer M, Tooker JF, Luthe DS, Felton GW (2009) Plants on early alert: glandular trichomes as sensors for insect herbivores. New Phytol 184:644-656. doi:10.1111/j.1469-8137.2009.03002.x

Pettersson J, Ninkovic V, Glinwood R, Birkett MA, Pickett JA (2005) Foraging in complex environment-semiochemicals support searching behaviour of the seven spot ladybird. Eur J Entomol 102:365-370

Pettersson J, Tjallingii WF, Hardie J (2007) Host-plant selection and feeding. In: van Emden H, Harrington R (eds) Aphids as crop pest, vol 4. CAB International, Wallingford, pp 87-113

Pettersson J, Ninkovic V, Glinwood R, Al Abassi S, Birkett M, Pickett J, Wadhams LJ (2008) Chemical stimuli supporting foraging behaviour of Coccinella septempunctata L. (Coleoptera: Coccinellidae): volatiles and allelobiosis-a mini review. Appl Entomol Zool 43:315-321. doi:10.1303/aez.2008.315

Powell G, Hardie J, Pickett JA (1993) Effects of the antifeedant polygodial on plant penetration by aphids, assessed by video and electrical recording. Entomol Exp Appl 68:193-200. doi:10. 1111/j.1570-7458.1993.tb01703.x
Prado E, Tjallingii WF (1997) Effects of previous infestation on sieve element acceptance by two aphids. Entomol Exp Appl 82:189-200. doi:10.1046/j.1570-7458.1997.00130.x

Quiroz A, Pettersson J, Pickett JA, Wadhams LJ, Niemeyer HM (1997) Semiochemicals mediating spacing behavior of bird cherry-oat aphid, Rhopalosiphum padi, feeding on cereals. J Chem Ecol 23:2599-2607. doi:10.1023/B:JOEC.0000006669.34845.0d

Rützler M, Zwiebel LJ (2005) Molecular biology of insect olfaction: recent progress and conceptual models. J Comp Physiol A Neuroethol Sens Neural Behav Physiol 191:777-790. doi:10. 1007/s00359-005-0044-y

SAS Institute Inc (2011) SAS/Stat User's Guide, Version 9. SAS Institute Inc, Cary, NC

Shepherd RW, Wagner GJ (2007) Phylloplane proteins: emerging defenses at the aerial frontline? Trends Plant Sci 12:51-56. doi:10.1016/j.tplants.2006.12.003

Smith CM (1988) Effects of mechanical damage to plants on insect populations. In: Heinrichs EA (ed) Plant stress-insect interactions, vol 9. Wiley, New York, pp 321-340

StatSoft, Inc. 2011 STATISTICA (data analysis software system), version 10.0 StatSoft, Tulsa, OK, USA

Telewski FW (2006) A unified hypothesis of mechanoperception in plants. Am J Bot 93(10):1466-1476. doi:10.3732/ajb.93.10.1466

Tretner C, Huth U, Hause B (2008) Mechanostimulation of Medicago truncatula leads to enhanced levels of jasmonic acid. J Exp Bot 59:2847-2856. doi:10.1093/jxb/ern145

Van Emden HF, Macklin RJ, Staunton-Lambert S (1990) Stroking plants to reduce aphid populations. Entomologist 109:184-188

Webster B (2012) The role of olfaction in aphid host location. Physiol Entomol 37:10-18. doi:10.1111/j.1365-3032.2011.00791.x

Wei JN, Zhu JW, Kang L (2006) Volatiles released from bean plants in response to agromyzid flies. Planta 224:279-287 